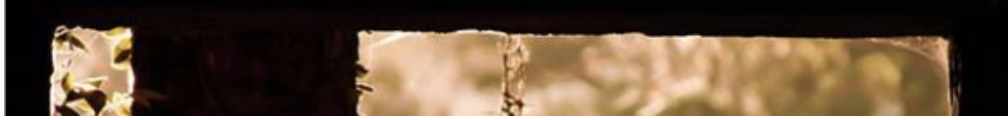

\title{
FORMAÇÃO DO ADOLESCENTE NO ENSINO MÉDIO INTEGRADO: CONTRIBUIÇÕES DA PSICOLOGIA HISTÓRICO-CULTURAL
}

\author{
ADOLESCENT FORMATION IN VOCATIONAL SECONDARY \\ EDUCATION: CONTRIBUTIONS OF VYGOTSKY'S STUDIES
}

DOI: http://dx.doi.org/105965199431781212016058

Priscila de Souza Chisté - IFES

\begin{abstract}
RESUMO
$\mathrm{O}$ artigo em tela tem como objetivo compreender a importância do Ensino Médio Integrado como um modo de contribuir com a formação do adolescente. Para tanto, dialoga com autores que analisam a trajetória da Educação Profissional no Brasil e, de modo mais especifico, o Ensino Médio Integrado. Apresenta pressupostos da Psicologia Histórico-Cultural, no que se refere ao adolescente e à importância da educação escolar, com o objetivo de conhecer suas peculiaridades psicológicas e entender a importância do Ensino Médio Integrado como mediador dessa formação. Utiliza como abordagem metodológica a pesquisa bibliográfica e documental, tendo em vista que recorre a livros, a dissertações, a teses e a legislações para discorrer sobre o assunto. Conclui que o Ensino Médio Integrado é um lócus propício para a formação integral, desde que suas bases estejam sustentadas pelas ideias de formação politécnica, integral e omnilateral.
\end{abstract}

Palavras-chave: Ensino médio integrado; adolescência; formação humana.

\section{ABSTRACT}

The article on screen aims to understand the importance of Vocational Secondary Education as a way of contributing to adolescent formation. Therefore, it dialogues with authors who analyze the trajectory the vocational education in Brazil and, more specifically, the Vocational Secondary Education. This article features Cultural-historical Psychology assumptions in regard to adolescents and the importance of school education, with the goal of meeting their psychological peculiarities and understanding the importance of Vocational Secondary School as a mediator of such formation. As methodological approach, it uses the bibliographical and documentary research owing to the usage of books, dissertations, theses and legislation to descant on the subject. The article concludes that the Vocational Secondary Education is a conducive locus to integral formation provided that its bases are founded on polytechnic, integral and omnilateral formation ideas.

Keywords: Vocational Secondary Education; adolescence; human formation.

\section{INTRODUÇÃO}

A formação humana é um tema fundamental nas discussões educacionais. Contudo, quando se trata de Educação Profissional tal temática é recorrentemente menosprezada, pois o foco volta-se para a instrumentalização dos sujeitos, de modo a atender às demandas do mercado. Essa discussão toma 


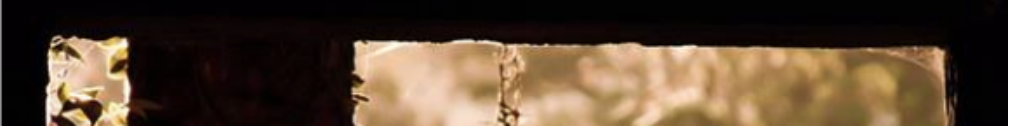

um novo caminho a partir do materialismo histórico-dialético ${ }^{1}$, nas figuras essenciais de Marx, no campo da filosofia, e de Vigotski, na psicologia pedagógica. Tais abordagens consideram o trabalho educativo como um modo de contribuir com a formação humana, com vistas à emancipação do sujeito, por meio de mediações ${ }^{2}$ que estimulem o desenvolvimento de todas as capacidades humanas.

Visando abordar essa temática, nosso objetivo é compreender, por meio da Psicologia Histórico-Cultural, a importância do Ensino Médio Integrado como um modo de contribuir com a formação do adolescente. Assim, sob a forma de pergunta, buscamos com o texto que segue refletir sobre a seguinte questão: Qual é a importância do Ensino Médio Integrado para a formação do adolescente?

\section{EDUCAÇÃO PROFISSIONAL NO BRASIL E O ENSINO MÉDIO INTEGRADO}

Na história da educação brasileira, a Educação Profisssional foi pensada para treinar uma parcela da população para o desempenho de atividades manuais consideradas de nível intelectual inferior, atender às demandas da indústria ou contemplar os grupos sociais desfavorecidos economicamente.

Seguindo esses objetivos, muitas foram as iniciativas e legislações elaboradas para Educação Profissional no Brasil. Tais propostas foram problematizadas, de modo especial,

\footnotetext{
${ }^{1} \mathrm{O}$ materialismo histórico-dialético é um método de interpretação da realidade. Entende a realidade como um processo, ou conjunto de processos, cuja essência está dada pelas contradições e cuja dinâmica é produzida pelas contradições que fazem parte desses processos. Defende a superação da dicotomia sujeito-objeto, pois considera que sujeito e objeto são dois aspectos de uma mesma realidade em contradição dialética e em unidade, visto que estão ligados entre si pela realidade objetiva. É materialista porque parte da ideia de que a realidade objetiva (matéria) existe antes de existir na consciência, ou seja, compreende que nada pode existir no cérebro que não encontre na realidade objetiva sua origem. A realidade objetiva (matéria) encontra-se em movimento e é constituída por contradições, do mesmo modo que a consciência é dinâmica, e se encontra em movimento pelas mesmas contradições. A realidade objetiva é histórica, sua explicação exige que se mostre sua dimensão diacrônica, que ocorreu ao longo da história, permitindo ver essa realidade como processo em desenvolvimento. Esse processo, além de histórico, é dialético, pois parte da análise de polos contraditórios com concepções próprias da realidade, que em um confronto supera o momento anterior, produzindo, através da própria ação sobre a realidade, uma nova realidade pensada, uma nova criação cultural. Tal processo pode ocorrer nos indivíduos, nos grupos humanos e sociedades, mas também no desenvolvimento da própria espécie humana.

${ }^{2}$ A relação do homem com o real é sempre mediada. Mediada pelo outro e pelos signos. É no curso das relações sociais que os indivíduos produzem, apropriam-se e transformam as diferentes atividades práticas e simbólicas em circulação na sociedade em que vivem e as internalizam como modos de ação/elaboração próprios, constituindo-se como sujeitos. Assim, para o indivíduo se constituir como ser humano, é preciso que internalize as produções humanas que foram sistematizadas na trajetória da humanidade. Nesse contexto, para se conhecer um objeto, é preciso revelar sua estrutura social, apresentar o mundo das mediações, dos processos sociais (econômicos, políticos, científicos etc.) em que o objeto está inserido. Dentre as práticas sociais, a educação é mediação que funciona como organizadora e transmissora de ideias, medeia as ações executadas no contexto educativo (CURY, 2000).
} 
durante as décadas de 1980 e 1990, por um grupo de intelectuais influenciados pela tradição marxiana e suas implicações na educação. Dentre eles, podemos citar Machado (1991), Saviani (1989), Manacorda (1991), Enguita (1994), Franco (1991), Kuenzer (1995), entre outros.

Concomitante a essas discussões, mas distante da base epistemológica marxiana, ocorreu no Congresso Nacional, o processo que culminou com a criação de uma nova Lei de Diretrizes e Bases (LDB), a Lei $n^{\circ}$ 9.394/1996, elaborada nos moldes do ideário neoliberal. Apesar da implementação da nova LDB, na ocasião, estávamos longe da construção de uma escola única, capaz de superar a dualidade da formação dos jovens (formação técnica $\mathrm{x}$ formação humana). Assim, ficou evidenciado que as políticas públicas e a legislação relacionada com o Ensino Médio e a Educação Profissional promovidas a partir da década de 1990 não apresentavam interesse pela formação humana.

Com o fim do governo de Fernando Henrique Cardoso, uma nova chance para a integração entre o Ensino Médio e a Educação Profissional aconteceu, pela via da publicação do Decreto $\mathrm{n}^{\circ}$ 5.154/2004, incorporado à LDB $\mathrm{n}^{\circ}$ 9.394/1996, por meio da Lei $\mathrm{n}^{\circ}$ 11.741/2008. A discussão sobre as leis anteriores resultou em uma significativa mobilização dos setores educacionais vinculados ao campo da Educação Profissional, principalmente no âmbito dos sindicatos e dos pesquisadores da área Trabalho e Educação. Desse modo, durante o ano de 2003 e até julho de 2004, houve grande efervescência nos debates que promoviam discussão sobre as relações entre o Ensino Médio e a Educação Profíssional.

Tais reflexões conduziram ao entendimento de que uma solução transitória e viável seria um tipo de Ensino Médio que garantisse a integralidade da educação básica, ou seja, que contemplasse o aprofundamento dos conhecimentos científicos produzidos e acumulados historicamente pela sociedade, e também abarcasse os objetivos da formação profissional, em uma visão da integração das dimensões humanas e tecnológicas. Essa perspectiva, ao adotar a ciência, a tecnologia, a cultura e o trabalho como eixos estruturantes, contemplaria as bases em que se poderia desenvolver uma educação tecnológica ou politécnica e, ao mesmo tempo, uma formação profissional exigida pela dura realidade socioeconômica do País. "O Ensino Médio integrado ao ensino técnico, sob uma base unitária de formação geral, é uma condição necessária para se fazer a travessia para uma nova realidade" (FRIGOTTO; CIAVATTA; RAMOS, 2005, p. 43). 


\section{EDUCAÇÃO, ARTES E INCLUSÃO}

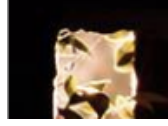

Foi a partir dessa discussão que se edificaram as bases que deram origem ao Decreto $\mathrm{n}^{\circ}$ 5.154/2004. Esse instrumento legal, além de manter as ofertas dos cursos técnicos concomitantes e subsequentes, por meio do Decreto $n^{\circ} 2.208 / 1997$, teve o grande mérito de revogá-lo e de trazer de volta a possibilidade de integrar o Ensino Médio à Educação Profissional, agora, numa perspectiva que não se confundia totalmente com a educação politécnica, mas que apontava em sua direção, porque continha os princípios de sua construção. Diante dessas premissas, na próxima seção, apresentaremos os conceitos de Politecnia, com vistas a ampliar a discussão.

\section{CAMINHOS EM BUSCA DA POLITECNIA}

Politecnia diz respeito ao "[...] domínio dos fundamentos científicos das diferentes técnicas que caracterizam o processo de trabalho moderno" (SAVIANI, 2003, p. 140). A partir dessa concepção, o ensino deveria concentrar-se nas modalidades fundamentais que dão base à multiplicidade de processos e técnicas de produção existentes. O ideário gramsciano em que se insere a Politecnia busca romper com a dicotomia entre a educação básica e a técnica e resgatar o princípio da formação humana em sua totalidade. Em termos epistemológicos e pedagógicos, esse ideário defende um ensino que integre ciência e cultura, humanismo e tecnologia. Visa ao desenvolvimento de todas as potencialidades humanas e propõe uma formação distanciada do humanismo liberal, voltado para o ensino memorístico, mas que contribua para o desenvolvimento da capacidade de criação intelectual e prática do sujeito, além de proporcionar a compreensão da totalidade social, tendo o trabalho como princípio educativo, ou seja, como base para a sua formação (MOURA, 2013).

Na sociedade capitalista, a escola profissional significa, correntemente, uma escola de categoria inferior, destinada aos jovens desprovidos de recursos, corroborando a diferenciação social (MACHADO, 1991). De modo contrário, na escola do trabalho socialista, sob a égide da Politecnia, os conhecimentos técnicos e práticos têm um nível de compreensão intelectual que visa promover as condições para a supressão dos mecanismos reprodutores da desigualdade cultural e social. Essa escola teria como objetivo ser mais que um vínculo de difusão dos novos princípios sociais. Ela se caracterizaria “[...] como uma influência organizada do proletariado sobre as demais classes, com o intuito de criar as novas gerações, 


\section{EDUCAÇÃO, ARTES E INCLUSÃO}

capazes de promover o prosseguimento da revolução até a completa transformação da sociedade" (MACHADO, 1991, p. 152).

A escola politécnica não seria aquela “[...] onde se estudam muitos ofícios, mas onde se ensina às crianças a compreender a essência dos processos de trabalho, a substância da atividade laboriosa do povo e as condições de êxito no trabalho. É uma escola onde as crianças aprendem a medir a extensão de suas faculdades" (MACHADO, 1991, p. 156). Nesse sentido, o ensino politécnico é aquele destinado a desenvolver uma cultura geral do trabalho, o que pressupõe a compreensão da produção em seu conjunto, o conhecimento da direção em que se desenvolvem a técnica e as mudanças tecnológicas.

No plano pedagógico, em se tratando da escola de Ensino Médio, essa proposta de articulação entre o trabalho e o ensino pressupõe a integração de todas as disciplinas, saturando-as, ao máximo, com as questões e os desafios concretos suscitados pela atividade laborativa. Tal forma de integração tem por objetivo, no seu limite, romper com a fragmentação do conhecimento. A formação politécnica deve penetrar todas as disciplinas e se traduzir na escolha do ensino, tanto da Física como da Química, tanto das Ciências Naturais como das Ciências Sociais. Assim, a escola politécnica visa pôr o aluno em contato com a herança cultural e ser uma escola criadora, capaz de desenvolver a personalidade e a autonomia do discente. Uma escola cujo objetivo básico é desenvolver o alicerce cultural sólido e durável, capaz de acompanhar o indivíduo em sua trajetória, útil às suas atividades de trabalho e de vida, independentemente da especificidade exercida. Nesse contexto, mostra-se muito relevante recuperar os conceitos de Integração e de Omnilateralidade e enfatizar suas vitalidades para a estruturação do Ensino Médio Integrado.

\section{INTEGRAÇÃO E OMNILATERALIDADE NO ENSINO MÉDIO INTEGRADO}

Para Ciavatta (2005), é preciso buscar as origens do termo integrar a partir das ideias de Gramsci, com um sentido de completude, de compreensão das partes no seu todo ou da unidade no diverso, de tratar a educação como totalidade social, isto é, nas múltiplas mediações históricas que concretizam os processos educativos.

[...] queremos que a educação geral se torne inseparável da Educação Profissional em todos os campos onde se dá a preparação para o trabalho: seja nos processos produtivos, seja nos processos educativos como a formação inicial, como o ensino 
técnico, tecnológico ou superior. Significa que buscamos enfocar o trabalho como princípio educativo, no sentido de superar a dicotomia trabalho manual/trabalho intelectual, de incorporar a dimensão intelectual ao trabalho produtivo, de formar trabalhadores capazes de atuar como dirigentes e cidadãos (CIAVATTA, 2005, p. 84).

Segundo o Documento-Base para a Educação Profissional Técnica de Nível Médio Integrada ao Ensino Médio (BRASIL, 2007), o sentido de integração expressa uma concepção de formação humana, com base na integração de todas as dimensões da vida no processo educativo e visa à formação omnilateral dos sujeitos.

Para Manacorda (1991), em frente à realidade da alienação humana, na qual todo homem alienado por outro encontra-se alienado da sua própria natureza, está a exigência da omnilateralidade. A omnilateralidade refere-se a um desenvolvimento total, completo, multilateral, em todos os sentidos das faculdades e das forças produtivas, das necessidades e da capacidade humana. Segundo esse autor, Marx, nos Manuscritos de 1844, utiliza pela primeira vez a expressão "omnilateral" quando diz que "[...] o homem se apropria de uma maneira omnilateral do seu ser omnilateral, portanto como ser total” (MARX, 2004, p. 108). Nesse sentido, omnilateralidade é a chegada histórica do homem a uma totalidade de capacidades produtivas e, ao mesmo tempo, a uma totalidade de capacidades de consumo e prazeres, em que se deve considerar sobretudo o gozo daqueles bens espirituais, além dos materiais, e dos quais o trabalhador tem estado excluído, em consequência da divisão do trabalho. A divisão do trabalho é reforçada pela escola e também é causadora da unilateralidade, pois não promove, muitas vezes, a interação entre a escola e a sociedade.

Diante dos conceitos de Integração e Omnilateralidade apresentados, faremos, a seguir, a exposição dos eixos do Ensino Médio Integrado.

\section{EIXOS DO ENSINO MÉDIO INTEGRADO: TRABALHO, CIÊNCIA E CULTURA}

A partir dessas bases (integração e omnilateralidade), Ramos (2005) aponta ser necessário criar um projeto de Ensino Médio que tenha como eixo o trabalho, a ciência e a cultura. Um projeto que garanta ao adolescente o direito a uma formação completa para a leitura de mundo e para a atuação crítica integrada à sua sociedade política. Essa formação supõe a compreensão das relações sociais subjacentes a todos os fenômenos (CIAVATTA, 2005), com a compreensão de que homens e mulheres são seres histórico-sociais que atuam 
no mundo concreto, para satisfazer suas necessidades subjetivas e sociais e, nessa ação, produzem conhecimentos.

Nos eixos que fundamentam o Ensino Médio Integrado, o trabalho é considerado como o princípio. Ele é mediação entre o homem e o objeto a ser investigado/conhecido, é o que confere significado a uma escola que se diz ativa e criadora. "Ter o trabalho como princípio educativo implica referir-se a uma formação baseada no processo histórico e ontológico de produção da existência humana, em que a produção do conhecimento científico é uma dimensão" (RAMOS, 2005, p. 119).

Ciavatta (2005) alerta que, apenas ao enfocar o trabalho na sua particularidade histórica, nas mediações específicas que lhe dão forma e sentido no tempo e no espaço, podemos apreendê-lo ou apreender o mundo do trabalho na sua historicidade, como atividade criadora. Porém, de modo contrário, na sociedade atual o trabalho pode ser penoso, capaz de alienar o ser humano de si mesmo, dos outros e dos produtos de seu trabalho sob a forma de mercadorias.

Ramos (2005) considera necessário integrar todas as dimensões da vida no processo educativo, pois o trabalho, a ciência e a cultura são categorias indissociáveis da formação humana. Essa concepção de trabalho associa-se à concepção de ciência, pois relaciona-se com conhecimentos produzidos, sistematizados e legitimados socialmente ao longo da história, como resultado de um processo empreendido pela humanidade, na busca da compreensão e da transformação dos fenômenos naturais e sociais (RAMOS, 2005). Portanto, a ciência conforma conceitos e métodos que são transmitidos para diferentes gerações e, ao mesmo tempo, que podem ser questionados e superados historicamente, no movimento permanente de construção de novos conhecimentos.

A outra dimensão da vida que precisa integrar o processo educativo é a cultura. Segundo Ramos (2005), a cultura deve ser entendida como diferentes formas de criação da sociedade, seus valores, suas normas de conduta e suas obras. Portanto, a cultura é tanto a produção ética quanto a produção estética de uma sociedade. Assim, pode-se compreender que os conhecimentos característicos de um tempo histórico e de um grupo social trazem a marca das razões, dos problemas, das necessidades e das possibilidades que motivaram o avanço do conhecimento em uma sociedade. 
Nesse sentido, a escola deve apresentar-se como escola da cultura e do trabalho, isto é, da ciência tornada produtiva e da prática tornada complexa, mantendo estreita relação com a vida coletiva. O significado marxista de prática não se identifica com a ação concreta e imediata de um indivíduo particular (ao cotidiano), outrossim, com a prática social e histórica do conjunto dos homens, disponibilizada aos seres singulares como base de suas realizações como seres sociais, ou seja, com a forma como estão sintetizadas as relações sociais em um determinado momento histórico. Contudo, apesar de existir legislação que oriente o Ensino Médio Integrado e também reflexões teóricas que contribuem com o seu processo de implementação, percebe-se que poucas são as instituições de ensino que de fato conseguiram se aproximar das prerrogativas relacionadas a essa modalidade de ensino. Pesquisas na área apontam que é necessário forte investimento político e pedagógico para que o Ensino Médio Integrado consiga integrar efetivamente os conteúdos que compõe o seu currículo. Assim, percebemos que longo é o caminho a ser traçado, para que seja possível implementar tais prerrogativas, pois a realidade marcada pelo capitalismo muitas vezes não oferece condições objetivas para atender a tais premissas.

Diante das ideias apresentadas, cabe, na seção seguinte, apresentar reflexões sobre aspectos psicológicos relativos ao aluno que frequenta o Ensino Médio Integrado. A ideia é conhecer as peculiaridades psicológicas do adolescente, de modo a contribuir com o entendimento da importância do Ensino Médio Integrado à Educação Profissional.

\section{ADOLESCÊNCIA E FORMAÇÃO HUMANA A PARTIR DA PSICOLOGIA HISTÓRICO-CULTURAL}

Os estudos que deram origem à Psicologia Histórico-cultural foram produzidos há mais de 80 anos, no contexto de consolidação do Socialismo na União Soviética. Na ocasião, diante de muitos desafios econômicos, políticos, culturais e sociais, a educação foi tida como prioridade desse país. A pedagogia soviética tinha como objetivo a formação do homem novo a partir do humanismo, do coletivismo, do respeito pelo indivíduo e do desenvolvimento integral das crianças e dos adolescentes como membros da sociedade.

Assim, Vigotski analisou a adolescência por meio de uma perspectiva histórica ampla de emancipação humana pela construção de uma nova sociedade, ou seja, a partir de uma visão de luta histórica pela liberdade na qual a adolescência necessitava ser compreendida 
como um momento crítico nessa direção. Dessa forma, a análise que Vigotski propõe sobre a adolescência compõe um cenário de busca por sistematizar estudos sobre o desenvolvimento psicológico individual para a construção do Socialismo. Pressupõe que a análise de qualquer fase do desenvolvimento da vida humana sempre tem como referência um posicionamento político. Para Vigotski, o desenvolvimento histórico da psicologia como ciência relaciona-se às concepções de um indivíduo e de uma sociedade que não seria possível de acontecer sob a efígie do capitalismo. Seria necessário superar o capitalismo pelo socialismo. Nas palavras de Vigotski (1991, p. 406): "Ser donos da verdade sobre a pessoa e da própria pessoa é impossível enquanto a humanidade não for dona da verdade sobre a sociedade e da própria sociedade. Pelo contrário, na nova sociedade [socialista], nossa ciência se encontrará no centro da vida".

Desse modo, sem compreender o contexto em que foram produzidos os estudos de Vigotski, fica difícil conceber a sua análise da adolescência como um período de transição entre o em-si da infância (relação imediata da criança com o ambiente) e o para-si (relação com o mundo e com a sociedade) da vida adulta. Para além de entender a adolescência como sinônimo de idade conturbada e problemática, Vigotski a compreende como um momento de superação, parte integrante do desenvolvimento do indivíduo.

Ao considerar a influência do contexto histórico na produção vigotskiniana, é importante destacar também outro ponto que envolve a complexidade dessa temática: a adolescência não é uma fase natural e eterna da espécie humana, mas um fenômeno histórico e social, produzido pelas sociedades dividas em classes sociais. Para Anjos (2013), a adolescência, enquanto fase do desenvolvimento psicológico, tem sua origem na história das transformações das sociedades, ou seja, nas transformações dos modos de produção. Para esse autor, a adolescência surgiu em consequência de um determinado grau, historicamente alcançado, de complexidade da vida social.

Até o século XVIII, em algumas sociedades, o indivíduo passava da infância para a fase adulta sem necessariamente passar pela condição da adolescência. As crianças cresciam junto com os adultos e aprendiam comportamentos sociais em contato com eles. No século $\mathrm{XIX}$, as crianças incorporavam-se ao mundo do trabalho entre os sete anos e o começo da puberdade. "Poucas crianças estudavam. Somente os filhos das classes altas e, as que estudavam, tinham em média de 10 ou 12 anos. Geralmente não estavam agrupadas em níveis 
de idades diferenciados, nem permaneciam muito tempo no sistema educacional" (ANJOS, 2013, p. 15).

Com as transformações na sociedade promovidas pela Revolução Industrial, houve a necessidade de uma adaptação da educação escolar vigente. Era preciso instituir uma formação escolar que atendesse às demandas do mercado. Porém, somente os filhos das classes mais abastadas permaneciam mais tempo na escola. "Os filhos de operários, mesmo em idades muito precoces, continuaram por longo tempo no mundo do trabalho" (ANJOS, 2013, p. 16).

Com a ampliação do tempo que passaram a ficar na escola, os adolescentes distanciaram-se da família e passaram a ficar mais tempo com outros adolescentes que frequentavam a escola. Formaram um novo grupo e constituíram uma nova fase do desenvolvimento. Anjos (2013, p. 16) alerta que esse distanciamento não foi causado "apenas pela inserção do adolescente na escola nem o prolongamento da adolescência fora reflexo do prolongamento do tempo de escolaridade. Isso, [...] aconteceu apenas com as camadas privilegiadas da sociedade, ou seja, com a burguesia".

Durante muito tempo os adolescentes pobres ficaram separados de seus familiares, devido aos contratos de trabalho no campo, ou devido à aprendizagem junto de um artífice distante. Além do trabalho no campo, a entrada no exército, no convento ou no seminário, que acontecia a partir dos 12 ou 13 anos de vida, também distanciou os adolescentes dos seus pais. Assim,

\footnotetext{
Enquanto a industrialização do século XIX obrigou as classes inferiores a uma infância muito curta, causando a dissociação das famílias de classe operária por serem compelidas a enviarem seus filhos para o trabalho a partir dos oito anos de idade, a burguesia, por sua vez, ofereceu longos estudos para seus filhos, no objetivo de prepará-los para os negócios econômicos (ANJOS, 2013, p. 16).
}

Atualmente, a adolescência é concebida como mais um nicho de mercado. O público dessa faixa etária consome produtos que se adequam ao seu perfil. Tais mercadorias reproduzem a "fase rebelde e problemática" em que estão inseridos, adequando-se ao público alvo. De modo contraditório, longe de serem entendidos como sujeitos irreverentes e perturbados pelos seus hormônios, como os entende a tendência biologizante, os adolescentes 
são modelados a permanecerem como consumidores passivos dos produtos já pensados para atender às suas "verdadeiras" necessidades.

Diante desse quadro, Duarte, Ferreira e Anjos (2014) alertam que buscar em Vigotski um conjunto de características universais da adolescência e aplicá-las à análise da educação contemporânea seria incorrer em erro. Cabe considerar que algumas características da adolescência apontadas por Vigotski são válidas para os dias atuais, sobretudo quando esse autor abarca uma perspectiva científica e filosófica sobre a adolescência. Para ele, o adolescente é um ser histórico e social. Portanto, é importante compreender que "as leis biológicas e as características determinantes do desenvolvimento humano pautadas na hereditariedade não são mais as forças motrizes do desenvolvimento humano, pois cederam lugar às leis sócio-históricas" (ANJOS, 2013, p. 17).

Além da compreensão da importância dos aspectos históricos e sociais, outro ponto importante refere-se à consideração da adolescência como um período em que linhas de desenvolvimento se articulam e se afetam, a saber: a dos interesses; a da formação dos conceitos e do desenvolvimento do pensamento; e a do desenvolvimento das funções psicológicas superiores. Assim, o ponto central desse período não são os conflitos, nem mesmo as mudanças corporais, biológicas, mas a formação dessas linhas de desenvolvimento do adolescente que colaboram com a compreensão da realidade em suas múltiplas determinações e com a inserção ativa desses sujeitos na sociedade.

Para Vigotski (1996), as etapas do desenvolvimento das funções psicológicas do ser humano, principalmente as do adolescente, ocorrem dentro de um complexo sistema hierárquico de novas formações psíquicas. As funções psicológicas superiores referem-se a processos voluntários, ações conscientemente controladas, mecanismos intencionais, como a consciência, a vontade, a intenção, que pertencem à esfera da subjetividade. Elas não se relacionam apenas com o desenvolvimento das funções como memória, atenção, percepção da realidade, mas também com o desenvolvimento da personalidade e da concepção de mundo. As funções psicológicas superiores envolvem o domínio de meios externos de desenvolvimento da cultura e do pensamento, como a linguagem, a escrita, o cálculo e o desenho. Exigem a utilização significativa de mediadores e se vinculam diretamente ao processo de escolarização. 
A função principal dessas novas formações é o desenvolvimento do pensamento a partir da formação de conceitos. Para Vigotski (1996), conceito é uma formação qualitativamente nova, uma nova forma de atividade intelectual, um novo modo de conduta, um novo mecanismo intelectual. É um ato real e complexo de pensamento que não se prende à memorização, é um ato de generalização que evolui com o significado das palavras e pode transitar de uma generalização para outra. Todas as restantes funções unem-se a essa formação nova, compondo uma síntese complexa. Com a formação dos conceitos, abre-se diante do adolescente o mundo da consciência social objetiva, o que torna possível a compreensão, a abstração e a síntese.

Com o desenvolvimento desses novos elementos, o adolescente é capaz de sair dos limites dos dados concretos, de entender os conceitos abstratos e as relações entre os fenômenos. Torna-se, então, capaz de compreender a si mesmo e de formar uma concepção de mundo, pois internaliza ideias, conceitos e valores, amplia suas possibilidades de ação na realidade social. "A formação de conceitos abre diante do adolescente o mundo da consciência social e impulsiona inevitavelmente o intenso desenvolvimento da psicologia e da ideologia de classes, a sua formação" (VIGOTSKI, 1996, p. 66).

Quando passa a dominar conceitos, o adolescente alcança um nível superior em seu pensamento, o que indica novas formas de atividade intelectual. Engendram-se as concepções sobre a vida, a sociedade, as pessoas, enfim, sobre o mundo a seu redor. Por meio desse processo, o adolescente domina o fluxo de seus processos psicológicos, orientando-se para a resolução dos problemas que surgem e que exigem o desenvolvimento de formas superiores do pensamento para poder solucioná-los. Nesse sentido, passa a apresentar ideias articuladas, embasadas e reflexivas sobre si, sobre o outro e sobre o mundo.

Assim, podemos considerar que a adolescência é marcada pelo crescimento de uma atividade crítica, pelo surgimento de interesses teóricos e pela necessidade de conhecer a realidade. Isso porque o adolescente passa a participar mais intensamente da realidade social, o que é possibilitado pelo desenvolvimento psíquico e pela capacidade maior de abstração que lhe é conferida por meio da formação de conceitos. Tal desenvolvimento também permite uma maior compreensão da realidade e favorece a inserção do adolescente no meio cultural, principalmente na escola. 
No adolescente, a atividade principal ou atividade-guia ${ }^{3}$ é estudar na escola e, nesse contexto, estabelecer relações pessoais com seus pares. Essa atividade é uma forma de reproduzir, com os outros adolescentes, as relações existentes entre os adultos. Tais relações efetivam-se a partir do respeito, da confiança e são importantes para a formação da sua personalidade. Para Anjos (2013), a história do desenvolvimento da personalidade do adolescente é constituída por três leis fundamentais.

A primeira lei é aquela que regula o desenvolvimento e a estrutura das funções psíquicas superiores. Desse modo, a mudança da estrutura da personalidade é caracterizada pelo salto qualitativo das funções psíquicas elementares que são incorporadas às funções psíquicas superiores. As funções superiores são consideradas como continuação das funções elementares. Essa primeira lei consiste na transformação das funções imediatas, espontâneas, nas funções voluntárias e intencionais. Anjos (2014, p. 231) nos ajuda a compreender essa transformação quando explica:

Por exemplo: o homem primitivo, ao criar pela primeira vez um signo exterior para lembrar-se de algo, consequentemente, já passaria a uma nova forma de memória, ou seja, a passagem da memorização involuntária à memorização regulada por signos. Isso quer dizer que, ao introduzir meios artificiais externos para recordar-se de algo, ele passa a dominar o processo de sua própria memorização.

A segunda lei refere-se ao fato de que as relações entre as funções psíquicas superiores foram anteriormente relações reais entre os homens. Assim, todas as funções psíquicas superiores "são relações de ordem social que, ao serem internalizadas, constituem a base da estrutura social da personalidade. As funções psíquicas superiores são produto das formas coletivas de comportamento" (ANJOS, 2014, p. 232). Desse modo, a natureza psíquica do ser humano é caracterizada por um conjunto de relações sociais que são internalizadas pelo indivíduo e convertidas em funções da personalidade.

A Terceira lei refere-se ao fato de que as funções psicológicas, a princípio, são

\footnotetext{
${ }^{3}$ Atividade-guia é a atividade que promoverá o maior desenvolvimento naquela etapa do indivíduo. "Uma atividade-guia não é a que mais tempo ocupa a criança, mas a atividade que carrega fatores valiosos e que contém elementos estruturais que impulsionam o desenvolvimento, ou seja, guia o desenvolvimento psíquico infantil. Durante o desenvolvimento humano, pode-se elencar algumas atividades-guia. Elkonin (1987) apresenta uma caracterização detalhada das épocas e dos períodos do desenvolvimento infantil desde o nascimento até a juventude: 1) a época da primeira infância, constituída pelo período da comunicação emocional direta com os adultos, seguido da atividade objetal manipulatória; 2) a época da infância, caracterizada pelo jogo de papéis (na idade pré-escolar) e pela atividade de estudo (na idade escolar) e 3 ) a adolescência, constituída pelo período da comunicação íntima pessoal, seguida pela atividade profissional e de estudo.
} 
operações externas que o indivíduo realiza com o auxílio do emprego de signos que permitem ao sujeito realizar operações cada vez mais complexas sobre os objetos e sobre o outro. Um exemplo simples que se pode pensar refere-se ao conselho dado por um familiar ou amigo sobre um risco iminente. $\mathrm{O}$ adolescente não precisa experimentar o infortúnio, ele pode lembrar da conversa que teve e que internalizou e, a partir dai, já não precisa mais das advertências dos amigos e familiares para evitar tal acidente. Portanto, faz-se necessária a mediação do uso de signos, para que o indivíduo possa influenciar o comportamento de outros indivíduos.

Desse modo, fica evidente que o processo de desenvolvimento das funções psíquicas superiores ocorre pela passagem das relações sociais externas ao interior do indivíduo, constituindo a base fundamental da formação da personalidade. "[...] Tudo aquilo que era a princípio exterior - convicções, interesses, concepção de mundo, normas, éticas, regras de conduta, tendências, ideais, determinados esquemas de pensamento - passa a ser interior" (VIGOTSKI, 1996, p. 63). Assim, as três leis apresentadas indicam o caráter social do desenvolvimento da personalidade do adolescente que permite a identificação com os adultos e com outros adolescentes. Eles encontram modelos para a imitação e para a construção de suas relações com as pessoas. Tais relações podem ser ampliadas no espaço escolar. A escola é um espaço de conhecimento, um espaço de encontros e convívio entre adolescentes e entre adolescentes e professores. Ela é também um espaço de criação.

Vigotski considera que a imaginação e a criatividade estão relacionadas com a livre elaboração dos elementos da experiência, e essa combinação “[...] exige, como premissa indispensável, a liberdade interna do pensamento, da ação, do conhecimento alcançado tão só aos que dominam a formação de conceitos. [Qualquer] alteração na formação de conceitos reduz a imaginação e a criatividade" (VIGOTSKI, 1996, p. 207).

Martins (2012) ajuda-nos a compreender que desenvolvimento psíquico corresponde a intelectualização de todas as funções psicológicas superiores, dentre elas também a imaginação. Destarte, pode-se considerar a poesia tão necessária quanto a geometria e, nesse contexto, a imaginação, a criatividade, a fantasia e os próprios sentimentos não são "entes autônomos, independentes de todo o sistema psíquico. Pelo contrário, seu desenvolvimento resulta e se vincula, sobretudo, à formação do pensamento abstrato, isto é, a um alto grau de desenvolvimento conceitual" (MARTINS, 2012, p. 10). Com isso, fica clara que, no âmbito da educação escolar direcionada à formação de conceitos científicos, a impossibilidade de 
qualquer hierarquização de conhecimentos. A valorização de tais conhecimentos, em igual medida, também está presente nas ideias sobre a Educação Integral propostas anteriormente neste texto. Cabe relembrar que para Marx a formação omnilateral refere-se a todas dimensões humanas. Precisamos nos apropriar de maneira omnilateral das objetivações humanas para nos constituirmos como um ser completo. Quais seriam, então, as premissas para o desenvolvimento integral do adolescente?

\section{PREMISSAS PARA O DESENVOLVIMENTO INTEGRAL: A IMPORTÂNCIA DA ESCOLA}

Para que tal desenvolvimento integral ocorra, é necessário que os conhecimentos sejam apropriados como ferramentas e instrumentos de compreensão da realidade. Precisam ser formados os instrumentos cognitivos para tal, que colaborarão com o desenvolvimento e com a compreensão da realidade, por meio de generalizações e abstrações que levarão essa compreensão para além do aparente. Nesse sentido, não basta compreender como se dá o desenvolvimento do ser humano, suas peculiaridades e características. Para Vigotski, é necessário organizar também a prática educativa, para criar novas necessidades e novos níveis de pensamento.

Portanto, cabe à escola proporcionar que a atividade de ensino envolva a análise e a reflexão de diversos tipos de conceitos. Um dos modos de atingir tal resultado, como sugere Saviani (1989), é partir da análise da prática social global, ou seja, da forma como estão sintetizadas as relações sociais em um determinado momento histórico, para, a seguir, colocar em xeque as respostas dadas à prática social, questionando essas indagações, assinalando suas insuficiências e incompletudes. Diante dessas questões, cabe oferecer condições para que o aluno compreenda o objeto de estudo em suas múltiplas determinações, o que demanda a apropriação de novos conhecimentos. Tal apropriação ocorrerá pela via da mediação intencional do professor, que colaborará com a ampliação das elaborações do pensamento, com sínteses, reflexões e catarses acerca do vivido. A partir desse processo de vivências, reflexões, mediações, apropriações e de momentos em que o aluno manifesta o que apreendeu, o sujeito, enriquecido pelas objetivações humanas, retorna à prática social em outro plano. Uma nova esfera que permita não apenas a compreensão da realidade em suas múltiplas relações, mas também que impulsione uma ação mais transformadora em face deste 
contexto, uma modificação da prática social proporcionada pela aprendizagem resultante da prática educativa.

A escola, quando bem organizada, age significativamente nesse processo, pois pode estimular e produzir a aprendizagem e o consequente desenvolvimento do indivíduo. Esse desenvolvimento não se dá automaticamente, não é inato, mas compõe um processo que é social, que ocorre nas relações com as outras pessoas, em uma realidade que é histórica e cultural.

Assim, segundo Martins (2012), a educação escolar é um processo que interfere diretamente na formação integral dos educandos, ou seja, em todas as dimensões possíveis. Tal prerrogativa dialoga com o que foi apontado quando tratamos da formação omnilateral dos alunos que frequentam o Ensino Médio Integrado, pensado a partir da politecnia e dos três eixos, trabalho, ciência e cultura. O trabalho, na sua particularidade histórica, como atividade criadora; a ciência, compreendida como conjunto de conhecimentos produzidos e legitimados socialmente, que buscam a compreensão e a transformação dos fenômenos naturais e sociais; e a cultura, entendida como produção ética e estética, que traz a marca dos problemas e das possibilidades que motivaram o avanço do conhecimento em uma sociedade.

Desse modo, é importante compreender que, para a educação escolar promover desenvolvimento, o ensino não é aquele que reproduz na escola somente os saberes de senso comum; mas aquele que promove a apropriação dos conteúdos clássicos, ou seja, daqueles que se firmaram como essenciais, como elementos culturais fundamentais ao processo de humanização.

Isso não significa que a educação escolar deva desconsiderar o cotidiano do aluno, fato considerado impossível. Pelo contrário, favorecer a apropriação dos conhecimentos científicos é a possibilidade de formação de indivíduos que mantenham uma relação cada vez mais consciente com a cotidianidade, mediada pela apropriação das objetivações genéricas para si, como a ciência, a arte e a filosofia (DUARTE, 1993).

Em suma, a escola é lócus do saber historicamente sistematizado. É um espaço privilegiado para a socialização desse saber. É a instituição social que deve prezar pelo ensino de conhecimentos que incidam sobre o desenvolvimento dos indivíduos e sobre as contradições sociais por eles enfrentadas, ou seja, ela necessita posicionar-se a favor da plena formação humana. 
As ideias marxianas que sustentam as teorias de Vigotski, apontam que a apropriação do patrimônio cultural produzido pela humanidade é imprescindível para a existência ativa dos indivíduos. A apreensão imediata da realidade não assegura tal apropriação, por isso a ênfase dada no ensino dos conhecimentos clássicos. "Apenas como resultado das complexas mediações do pensamento é que o objeto da captação torna-se inteligível e, assim sendo, é enquanto abstração mediadora na análise do real que o ensino da filosofia, da ciência, da arte, etc., adquire sua máxima relevância” (MARTINS, 2012, p. 12).

Contudo, Martins (2012) alerta que a teoria, por si mesma, não transforma a realidade, mas, para que ocorra essa transformação, é necessária uma formação que habilite os sujeitos a promovê-la.

Se, por um lado, a construção do conhecimento está diretamente ligada à atividade, esta, por si mesma, não é suficiente para engendrar a formação daquele. A atividade cognoscitiva e teleológica requer o registro e conservação das objetivações históricas e, ao mesmo tempo, a comunicação educativa entre os homens, pelos quais se realizam as apropriações de tais objetivações. Ou seja, demanda condições sociais de transmissão, demanda ensino, demanda uma sólida educação escolar! (MARTINS, 2012, p. 299).

A partir dessas colocações, e sem deixar de considerar que no interior da escola existem contradições que atravessam o trabalho pedagógico, pode-se pensar nos pressupostos do Ensino Médio Integrado - sua concepção integrada, omnilateral, politécnica e centrada nos eixos trabalho, ciência e cultura - como um modo de contribuir sobremaneira com a travessia em busca de uma educação emancipadora, capaz de colaborar com a formação psicológica do aluno. No Brasil, a falta a decisão política para assumir a omnilateralidade como sendo a concepção norteadora da formação de todos, independentemente da origem socioeconômica, vem impossibilitando iniciar a travessia. Conforme salienta Moura (2013, p. 718),

\footnotetext{
Infelizmente, a falta dessa decisão é coerente com o modelo de sociedade em que se vive, pautada pelo pensamento neoliberal que considera a desigualdade social como elemento indispensável ao fortalecimento dos mercados, já que é ela que potencializa a competitividade, alimento vital do mercado. Compreende-se, portanto, que o caminho para a travessia só poderá ser construído a partir de disputas políticas em meio às contradições do sistema capital.
}

Alguns movimentos recentes no âmbito do ensino médio e da educação profissional 
são esclarecedores dessas disputas e contradições. A começar pelas Diretrizes Curriculares Nacionais para a Educação Profissional Técnica de Nível Médio (BRASIL, 2012), que apesar de incorporarem alguns fundamentos de origem marxiana, reiteram uma concepção de formação humana com a centralidade nas competências e na lógica do mercado de trabalho, com ênfase nas certificações parciais e priorização das formas subsequentes e concomitantes ao ensino médio em detrimento do Ensino Médio Integrado.

Em meio a essas contradições, de modo a assegurar o que propõem tais Diretrizes, em seu artigo $5^{\circ}$, quando conceitua Trabalho a partir de sua perspectiva ontológica de transformação da natureza, como realização inerente ao ser humano e como mediação no processo de produção da sua existência, o MEC lançou, em 2013, o Pacto Nacional pelo Ensino Médio, envolvendo a adesão voluntária dos Estados Federativos. Uma das principais ações do Pacto foi um programa de formação continuada em serviço e remunerado com bolsa para os professores do ensino médio da rede pública de ensino. Assim como nas diretrizes, o trabalho como princípio educativo foi o eixo da formação continuada e do material utilizado para estudo pelos professores. "Este princípio, antes mesmo de se pensar aplicável na educação escolar, explica o processo histórico pelo qual a humanidade se fez existir. Ao transformar a realidade e a si mesmo pelo trabalho, o ser humano produz também conhecimento, tecnologia, cultura" (BRASIL, 2013, p. 29). Com todas as contradições e críticas que podem ser endereçadas ao Pacto, ele abriu um campo de disputa muito favorável à perspectiva educacional marxiana. Não por acaso, já se testemunha em 2015 o abandono dessa iniciativa pelo Governo Federal. Em alguns Estados brasileiros, assume o lugar da formação propiciada pelo Pacto o Programa Jovem de Futuro, desenvolvido pelas Secretarias Estaduais em parceria com o Instituto Unibanco e focado na Gestão Escolar para Resultados.

Outro ponto importante a ser levantado para a compreensão dos movimentos recentes, no âmbito do ensino médio e da educação profissional, refere-se à implementação do Programa Nacional de Acesso ao Ensino Técnico e Emprego (Pronatec), implementado em 2011, que, de modo estratégico, foi instituído antes das Diretrizes Curriculares Nacionais para a Educação Profissional Técnica de Nível Médio (2012) e também do Plano Nacional de Educação (2014-2024). O Pronatec tem como objetivo oportunizar a qualificação profissional no ensino fundamental e médio e atende pessoas que precisam de qualificação para inserção no mercado de trabalho. Os investimentos do programa reafirmam a importância dos cursos 
de formação inicial e continuada, mas não garantem avanços na escolaridade. Além disso, promove a parceria historicamente consolidada entre o público e o privado, legitimando a injeção de recursos públicos em instituições privadas que compõem o "Sistema S" (Senai, SESI e SESC). Em 2016, 2 milhões de vagas estão previstas para o Pronatec. Serão mais de 350 mil vagas em cursos técnicos e 1,6 milhão de vagas em cursos de qualifícação profissional.

Em meio a esse campo de contradições, é necessário avançar na direção de materializar a concepção de formação humana integral. Mostra-se muito relevante recuperar os conceitos de Integração e de Omnilateralidade e enfatizar sua vitalidade para a estruturação do Ensino Médio Integrado. Cabe pensar em modos de romper com a dualidade estrutural da educação escolar, mesmo sabendo que isso exigiria a transformação do modo de produção vigente. Contudo, isso não significa que devamos esperar que ocorra primeiramente a superação do atual modo de produção, para, somente depois, construirmos uma escola compatível com o novo o modo de produção. Como aponta Moura (2013, p. 719), "é preciso atuar em meio às contradições do modelo hegemônico vigente no sentido de produzir movimentos que contribuam para o rompimento da dualidade educacional, o que também contribuirá para a superação do sistema capital".

É preciso trabalhar para a construção da travessia a partir da consolidação do Ensino Médio Integrado e de sua concepção omnilateral, politécnica e centrada nos eixos trabalho, ciência e cultura, como um modo de contribuir sobremaneira com a travessia em busca de uma educação emancipadora, capaz de colaborar com a formação psicológica do aluno, para que esse se constitua como dirigente e atuante em uma sociedade menos desigual.

\section{REFERÊNCIAS}

ANJOS, Ricardo Eleutério dos. O papel da educação escolar no desenvolvimento da personalidade do adolescente. Nuances: estudos sobre Educação, São Paulo, v. 25, n.1, p. 228-246, jan./abr. 2014. Disponível em: http://revista.fct.unesp.br/index.php/Nuances/article/viewFile/2941/2529. Acesso em: 23-042016.

\section{. O desenvolvimento psíquico na idade de transição e a formação da}

individualidade para-si: aportes teóricos para a educação escolar de adolescentes. Araraquara, SP, 2013. 167f. Dissertação (Mestrado em Educação Escolar) - Universidade 


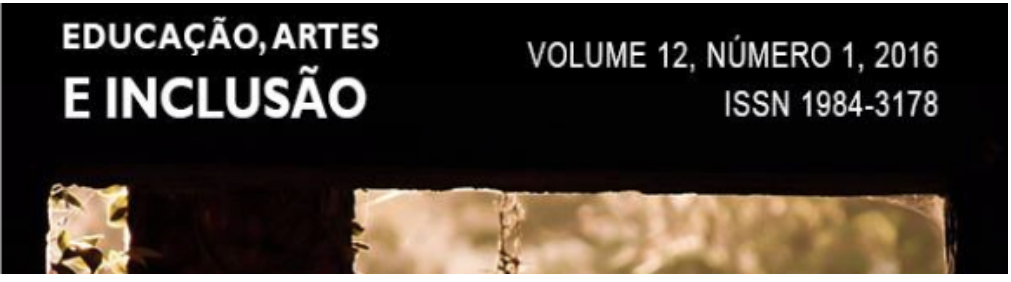

Estadual Paulista. Faculdade de Ciências e Letras, 2013.

BRASIL. Ministério da Educação e Cultura/Secretaria de Ensino Técnico. Educação profissional técnica de nível médio integrada ao ensino técnico: documento-base. Brasília: 2007.

. Formação de professores do ensino médio, etapa I - caderno IV: áreas de conhecimento e integração curricular / Ministério da Educação, Secretaria de Educação Básica. Curitiba: UFPR/Setor de Educação, 2013.

. Resolução $n^{\circ}$ 6, de 20 de setembro de 2012. Define diretrizes curriculares nacionais para a educação profissional técnica de nível médio. 2012. Disponível em: $<$ www.mec.org.br>. Acesso em: 10 jun. 2016.

CIAVATTA, Maria. A formação integrada: a escola e o trabalho como lugares de memória e de identidade. In: FRIGOTTO, Gaudêncio; CIAVATTA, Maria; RAMOS, Marise (Orgs.). Ensino médio integrado: concepção e contradições. São Paulo: Cortez, 2005.

CURY, Carlos Roberto Jamil. Educação e contradição: elementos metodológicos para uma teoria crítica do fenômeno educativo. São Paulo: Cortez, 2000.

DUARTE, N. A individualidade para-si: contribuição a uma teoria histórico-social da formação do indivíduo. Campinas: Autores Associados, 1993.

DUARTE, Newton; FERREIRA, Nathalia Botura de Paula; ANJOS, Ricardo Eleutério dos. Conceito ético-político de catarse e a importância da adolescência para a formação humana. In: OLIVEIRA, Avelino da Rosa; VALLE, Lílian do. Filosofia da educação: posições sobre a formação humana. Curitiba: Appris, 2014.

ENGUITA, Mariano Fernandez. A ideologia em Marx e a crítica a educação. Porto Alegre: Artes Médicas, 1944.

ELKONIN, D. B. Sobre el problema de la periodización del desarrollo psíquico en la infancia. In: V. Davidov; M. Shuare (Orgs.). La psicologia evolutiva e pedagógica en la URSS. URSS: Progresso, 1987.

FRANCO, Maria Ciavatta. O trabalho como princípio educativo: uma concepção unificadora de ciência, técnica e ensino. In: BRASIL. Politecnia no ensino médio. São Paulo-Brasília: Cortez/Ministério da Educação, 1991.

FRIGOTTO, Gaudêncio; CIAVATTA, Maria; RAMOS, Marise (Orgs.). Ensino médio integrado: concepção e contradições. São Paulo: Cortez, 2005.

GRAMSCI, Antonio. Os intelectuais e a organização da cultura. Rio de Janeiro: Civilização Brasileira, 1968.

KUENDER, Acácia. Pedagogia da fábrica: as relações de produção e a educação do trabalhador. São Paulo: Cortez, 1995.

MACHADO, Lucília Regina de Souza. Politecnia, escola unitária e trabalho. São Paulo: 


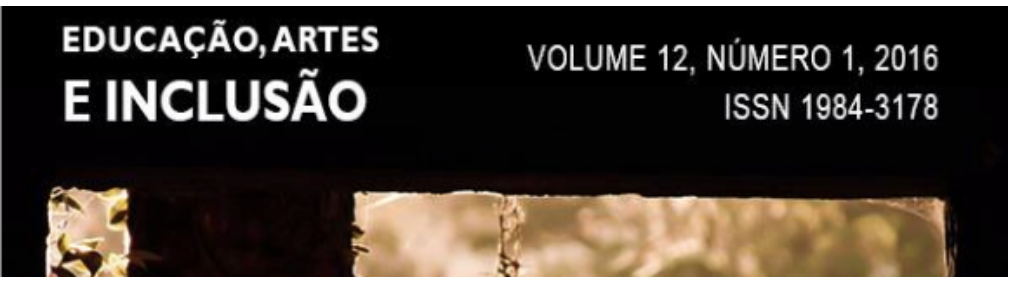

Editora Cortez/Autores Associados, 1991.

MANACORDA, Mario Alighiero. Marx e a pedagogia moderna. São Paulo: Cortez/Autores Associados, 1991.

MARTINS, Lígia Márcia. Contribuições da Psicologia Histórico Cultural para a Pedagogia Histórico-Crítica. In: VII Colóquio Internacional Marx e Engels, IFCH-UNICAMP, 2012. Disponível em:

http://www.ifch.unicamp.br/formulario_cemarx/selecao/2012/trabalhos/Ligia\%20Martins.pdf. Acesso em 26 abr. 2015.

MARX, Karl. Manuscritos econômico-filosóficos. São Paulo: Boitempo, 2004.

MOURA. Dante Henrique. Ensino médio integrado: subsunção aos interesses do capital ou travessia para a formação humana integral? Educação e Pesquisa, São Paulo, v. 39, n.3, p. 705-720, jul./set. 2013. Disponível em: http://www.scielo.br/pdf/ep/v39n3/10.pdf

PRESTES, Zoia. Quando não é quase a mesma coisa: traduções de Lev Semionovitch Vigotski no Brasil. Campinas, SP: Autores Associados, 2012.

RAMOS, Marise. Possibilidade e desafios na organização do currículo integrado. In: FRIGOTTO, Gaudêncio; CIAVATTA, Maria; RAMOS, Marise (Orgs.). Ensino médio integrado: concepção e contradições. São Paulo: Cortez, 2005.

RODRIGUES, J. Aeducaçãopolitécnica no Brasil. Niterói, RJ: Eduff, 1998.

SAVIANI, Dermeval. Sobre a concepção de politecnia. Rio de Janeiro: Fiocruz, 2003.

Escola e democracia. São Paulo: Cortez/Autores Associados, 1989.

VIGOTSKI, Lev Semenovich. Obras escogidas. Madrid: Visor, 1996, v. 4.

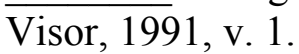

. El significado histórico de la crisis de la psicologia. In: Obras escogidas. Madrid: 